\section{Commentary: Second verse, same as the first: Biatrial versus bicaval anastomosis in cardiac transplantation}

\author{
David D. Yuh, MD, FACS, FACC
}

The relatively high prevalence of functional tricuspid insufficiency (TI) after orthotopic cardiac transplantation has been attributed to numerous factors (eg, endomyocardial biopsies, pulmonary hypertension, donor-recipient size mismatch, graft ischemic times) but most commonly to tricuspid annular distortion, which can result from the abnormal atrial dimensions and geometries associated with the "standard" biatrial cuff technique originally described by Shumway and Lower in the 1960s. ${ }^{1}$ Despite several studies demonstrating significant reduction of functional TI with the bicaval anastomotic technique introduced in the late $1980 \mathrm{~s}^{2,3}$ and others suggesting significant negative consequences of moderate to severe functional TI on morbidity and mortality among heart transplant recipients, ${ }^{4-6}$ the technically simpler biatrial technique is still widely performed today, with excellent results. The persistent comparisons of the 2 anastomotic techniques among multiple transplantation centers with widely varying rates of functional $\mathrm{TI}^{5}$ and inconsistent correlations with long-term survival ${ }^{7-10}$ have perpetuated controversy regarding these techniques' relative impacts on short- and long-term clinical outcomes.

The primary value of the analysis of a large cohort of biatrial cardiac transplant recipients reported by Hajiyev and colleagues ${ }^{11}$ in this issue of the Journal lies in its acceptance of the propensity for distorting tricuspid annular geometry and functional TI using the biatrial technique and identifying a technical benchmark-maintaining

\footnotetext{
From the Department of Surgery, Stamford Hospital, Stamford, Conn.

Disclosures: The author reported no conflicts of interest.

The Journal policy requires editors and reviewers to disclose conflicts of interest and to decline handling or reviewing manuscripts for which they may have a conflict of interest. The editors and reviewers of this article have no conflicts of interest.

Received for publication Aug 24, 2020; revisions received Aug 24, 2020; accepted for publication Aug 25, 2020; available ahead of print Sept 17, 2020.

Address for reprints: David D. Yuh, MD, FACS, FACC, Department of Surgery, Stamford Hospital, One Hospital Plaza, PO Box 9317, Stamford, CT 06904 (E-mail: DYuh@stamhealth.org)

JTCVS Open 2020;4:33-4

2666-2736

Copyright (C) 2020 The Authors. Published by Elsevier Inc. on behalf of The American Association for Thoracic Surgery. This is an open access article under the CC BY-NCND license (http://creativecommons.org/licenses/by-nc-nd/4.0/).

https://doi.org/10.1016/j.xjon.2020.08.014
}

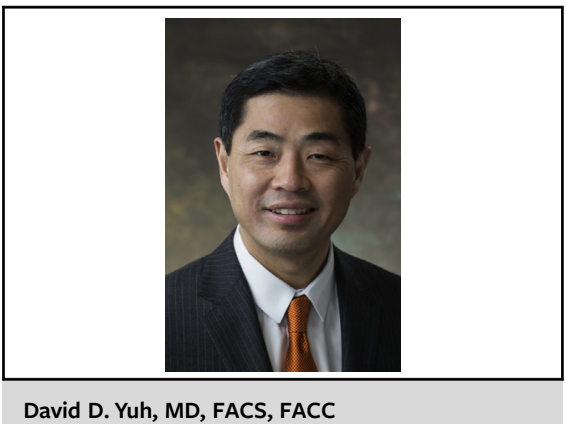

CENTRAL MESSAGE

Despite the purported advantages of the bicaval anastomotic technique in cardiac transplantation, tricuspid distortion and functional tricuspid insufficiency can be reduced with the stillpopular biatrial technique.

a donor-to-recipient $(\mathrm{D} / \mathrm{R})$ right atrial anterior wall ratio $<1$ - that mitigates this distortion by reducing tension on the anterior wall of the right atrium. The technique used by the authors' institution to achieve this benchmark appears to have resulted in a low incidence of early moderate to severe functional TI of $19 \%$, compared with $42.8 \%$ in a contemporary pooled meta-analysis ${ }^{12}$ and even higher rates in other series. ${ }^{5}$ The impact of right atrial proportions on functional TI was corroborated in an earlier study by Dandel and colleagues, ${ }^{13}$ who observed that patients without TI had a $\mathrm{D} / \mathrm{R}$ atrial dimensional ratio $<1$, whereas those with moderate to severe TI had a D/R ratio $>1$.

This technical benchmark for the biatrial technique illustrated by Hajiyev and colleagues provides a useful, reproducible refinement of a simple, time-tested technique for transplantation surgeons who are reluctant to change to an arguably more technically complicated bicaval technique despite its purported (yet still-controversial) benefits. Furthermore, the growing use of biventricular/AICDs and ventricular assist devices in patients awaiting transplantation and the improved survival ${ }^{14}$ may present more situations in which a biatrial anastomosis is more technically favorable (eg, reoperative transplant, abnormal caval veins).

Certainly, among cardiac transplant recipients there are more prevalent causes of morbidity and mortality than functional TI, regardless of its many possible etiologies (including anastomotic technique). Consistently mitigating 
the other risk factors identified by this analysis-number of endomyocardial biopsies and end-stage renal disease necessitating dialysis - would seem to be difficult. Nevertheless, there appears to be a significant opportunity to reduce the morbidity and mortality associated with functional TI after transplantation with improved surveillance and proactive medical and surgical interventions ${ }^{7}$ that includes reoperative and even prophylactic tricuspid annuloplasty during transplantation. ${ }^{15}$ Further validation and refinement of such measures would seem worthwhile.

\section{References}

1. Lower RR, Shumway NE. Studies on orthotopic homotransplantation of the canine heart. Surg Forum. 1960;11:18-9.

2. Dreyfus G, Jebara V, Mihaileanu S, Carpentier AF. Total orthotopic heart transplantation: an alternative to the standard technique. Ann Thorac Surg. 1991;52: 1181-4.

3. Sievers HH, Leyh R, Jahnke A, Petry A, Kraatz EG, Hermann G, et al. Bicaval versus atrial anastomoses in cardiac transplantation. Right atrial dimension and tricuspid valve function at rest and during exercise up to thirty-six months after transplantation. J Thorac Cardiovasc Surg. 1994;108:780-4.

4. Aziz TM, Saad RA, Burgess MI, Campbell CS, Yonan NA. Clinical significance of tricuspid valve dysfunction after orthotopic heart transplantation. J Heart Lung Transplant. 2002;21:1101-8.

5. Wong RCC, Abrahams Z, Hanna M, Pangrace J, Gonzalez-Stawinski G, Starling R, et al. Tricuspid regurgitation after cardiac transplantation: an old problem revisited. J Heart Lung Transplant. 2008;27:247-52.
6. Bishawi M, Zanotti G, Shaw L, MacKenzie M, Castleberry A, Bartels K, et al. Tricuspid valve regurgitation immediately after heart transplant and long-term outcomes. Ann Thorac Surg. 2019;107:1348-55.

7. Wartig M, Tesan S, Gäbel J, Jeppsson A, Selimovic N, Holmberg E, et al. Tricuspid regurgitation influences outcome after heart transplantation. J Heart Lung Transplant. 2014;33:829-35.

8. Weiss ES, Nwakanma LU, Russell SB, Conte JV, Shah AS. Outcomes in bicaval versus biatrial techniques in heart transplantation: an analysis of the UNOS database. J Heart Lung Transplant. 2008;27:178-83.

9. Sun JP, Niu J, Banbury MK, Zhou L, Taylor DO, Starling RC, et al. Influence of different implantation techniques on long-term survival after orthotopic heart transplantation: an echocardiographic study. J Heart Lung Transplant. 2007;26:1243-8.

10. Davies RR, Russo MJ, Morgan JA, Sorabella RA, Naka Y, Chen JM. Standard versus bicaval techniques for orthotopic heart transplantation: an analysis of the united network for organ sharing database. J Thorac Cardiovasc Surg. 2010;140:700-8.

11. Hajiyev V, Dandel M, Yeter R, Schoenrath F, Hennig F, Falk V, et al. Functional tricuspid valve insufficiency after cardiac transplantation: which factor is the most important. J Thorac Cardiovasc Surg Open. 2020;4:25-32.

12. Zijderhand CF, Veen KM, Caliskan K, Schoonen T, Mokhles MM, Bekkers JA, et al. Biatrial versus bicaval orthotopic heart transplantation: a systematic review and meta-analysis. Ann Thorac Surg. 2020;110:684-91.

13. Dandel M, Hummel M, Loebe M, Weng Y, Müller J, Buz S, et al. Right atrial geometry and tricuspid regurgitation after orthotopic heart transplantation: benefits of a modified biatrial surgical technique. J Heart Lung Transplant. 2001;20: 246-7.

14. Saito A, Novick RJ, Kiaii B, McKenzie FN, Quantz M, Pflugfelder P, et al. Early and late outcomes after cardiac retransplantation. Can J Surg. 2013;56:21-6.

15. Fiorelli AI, Stolf NAG, Abreu Filho CAC, Santos RHB, Buco FHA, Fiorelli LR, et al. Prophylactic donor tricuspid annuloplasty in orthotopic bicaval heart transplantation. Transplant Proc. 2007;39:2527-30. 